\title{
O gênero Callideriphus Blanchard, 1851 (Coleoptera, Cerambycidae, Heteropsini) ${ }^{1}$
}

\author{
Dilma Solange Napp ${ }^{2,4}$ \\ Ubirajara R. Martins $s^{3,4}$
}

\begin{abstract}
The genus Callideriphus Blanchard, 1851 (Coleoptera, Cerambycidae, Heteropsini). The genus Callideriphus comprises only two species: C. grossipes Blanchard, 1851 (type species) and C. tucumanus sp. nov. (Argentina, Tucumán). The type locality of $C$. grossipes had been originally indicated as Chile, but it is supposedly considered erroneous. Its distribution, actually, extends from Southeastern Brazil up to Argentina, along the Atlantic Forest. This species is extremely variable in regard to its coloration and elytral punctation. Two subspecies are recognized: C. grossipes grossipes Blanchard, 1851 (BRAZIL: Minas Gerais, Espírito Santo, São Paulo, Paraná, Santa Catarina) and C. grossipes flavipennis Melzer, 1934 (BRAZIL: Santa Catarina, Rio Grande do Sul; ARGENTINA: Chaco, Entre Ríos, Buenos Aires). Four intermediate forms are recorded and commented. Redescription and a key to species are added. Nomenclatural changes: Callideriphus grossipes grossipes Blanchard, $1851=$ C. grossipes var. brasliensis Melzer, 1923 syn. nov. $=$ C. rubricollis Melzer, 1934 syn. nov.; Callideriphus grossipes flavipennis Melzer, 1934 stat nov. = C. signaticollis Melzer, 1934 syn. nov.
\end{abstract}

Keywords. Callideriphus; Cerambycinae; Heteropsini; geographical distribution; taxonomy.

\section{INTRODUÇÃO}

Monné (1994) catalogou 19 espécies em Callideriphus Blanchard, 1851. Verificamos que as espécies até aqui inseridas em Callideriphus, na realidade, pertencem a quatro gêneros: Callideriphus, Unabiara Napp \& Martins, 2002,Eryphus Perty, 1832 e Tacyba Napp \& Martins, 2002 (NAPP \& MARTINs 2002a, b).

Também constatamos que a espécie-tipo de Callideriphus, C. grossipes Blanchard, 1851, originalmente descrita do Chile, não pertence à fauna chilena, mas sim à fauna do Brasil. Consideramos neste gênero apenas duas espécies, $C$. tucumanus sp. nov. e C. grossipes; esta, uma espécie extremamente variável em colorido e na pontuação elitral, habita a Floresta Ombrófila densa da Mata Atlântica e seus prolongamentos meridionais pelo vale do Prata até Buenos Aires. É subdividida, provisoriamente, em duas subespécies: C. g. grossipes Blanchard, 1851, no norte da distribuição e $C$. grossipes flavipennis Melzer, 1934, mais meridional.

As instituições arroladas no texto são: DZUP, Departamento de Zoologia, Universidade Federal do Paraná, Curitiba; MCNZ, Museu de Ciências Naturais, Fundação Zoobotânica do Rio Grande do Sul, Porto Alegre; MNHN, Muséum National d'Histoire Naturelle, Paris; MNRJ, Museu Nacional,
Universidade Federal do Rio de Janeiro, Rio de Janeiro; MZSP, Museu de Zoologia, Universidade de São Paulo, São Paulo.

Callideriphus Blanchard, 1851

Callideriphus Blanchard, 1851: 487; Monné, 1994: 38 (cat.).

Espécie-tipo: Callideriphus grossipes Blanchard, 1851, designação de Thomson, 1864: 201.

Corpo e apêndices com longos pêlos eretos, amareloesbranquiçados. Fronte plana, vertical, quase tão longa quanto larga, um pouco angulosa entre os tubérculos anteníferos. Estes pouco proeminentes, arredondados. Olhos finamente facetados, profundamente emarginados; lobos inferiores pouco desenvolvidos, laterais, mais longos que largos, acompanham o eixo vertical da fronte; ligados aos superiores por estreita faixa de 2-3 omatídios; lobos superiores estreitos, a distância entre os mesmos cerca de 5 vezes a largura de um lobo. Região posterior da cabeça abaulada. Genas com metade do comprimento dos lobos oculares inferiores. Mandíbulas delgadas, não angulosas, os ápices aguçados. Artículo apical dos palpos maxilares e labiais mais curto que os dois anteriores somados, truncado no ápice, cilíndrico nos machos, levemente dilatados nas fêmeas.

Antenas com 11 artículos, filiformes, desarmadas, sem

1. Contribuição ${ }^{\circ} 1305$ do Departamento de Zoologia, Universidade Federal do Paraná.

2. Departamento de Zoologia, Universidade Federal do Paraná. Caixa Postal 19020, 81531-980 Curitiba-PR, Brasil.

3. Museu de Zoologia, Universidade de São Paulo. Caixa Postal 42594, 04299-970 São Paulo-SP, Brasil.

4. Pesquisador do CNPq. 
sulcos ou carenas; no macho ultrapassam o ápice elitral em 23 artículos, nas fêmeas tão ou pouco mais longas que o corpo. Escapo subcilíndrico, sem sulcos ou depressões, pouco mais curto que o III e tão longo quanto o IV. Pedicelo com um terço do comprimento do antenômero III. Antenômero V o mais longo; III e XI subiguais, cerca de um quarto mais curtos que o V.

Protórax mais largo que longo, arredondado aos lados, mais atenuado na margem posterior. Pronoto com rugas longitudinais adensadas em toda a superfície; aos lados, após o meio, subtuberculado. Prosterno, nos machos, com duas grandes áreas de pontuação sexual, um pouco deprimidas e separadas, à frente do processo prosternal, por estreita faixa impontuada e mais elevada; áreas de pontuação sexual, opacas, irregularmente pontuado-corrugadas, com pubescência ereta, bem aparente. Processo prosternal muito estreito entre as procoxas, ligeiramente expandido no ápice. Cavidades coxais anteriores fortemente angulosas aos lados, o trocantin exposto, largamente abertas atrás. Procoxas um pouco cônicas e salientes. Mesosterno aplanado. Processo mesosternal com cerca de dois terços da largura de uma mesocoxa, os lados ligeiramente convergentes para o ápice, este com entalhe subanguloso para encaixe do metasterno. Mesocoxas globosas, salientes. Metasterno transverso, curto.

Élitros proporcionalmente curtos e largos, pouco mais longos que o dobro da largura umeral, aplanados no dorso, os lados paralelos até os ápices; estes largamente arredondados em conjunto, desarmados. Úmeros um pouco projetados para frente. Escutelo pequeno, triangular. Epipleuras ligeiramente sinuosas após os úmeros e praticamente não deiscentes para os ápices.

Pernas com comprimentos crescentes, as posteriores com quase o dobro do comprimento das anteriores. Fêmures fortemente clavados, as clavas algo achatadas, os pedúnculos curtos, sem sulco ou carenas, as abas apicais arredondadas. Metafêmures, no máximo, alcançam o início da curvatura apical dos élitros nos machos; nas fêmeas, nitidamente mais curtos. Tíbias cilíndrico-deprimidas, sem carenas. Esporões tibiais longos, o interno mais notavelmente. Escovas tarsais sem faixa glabra. Primeiro metatarsômero mais longo que os dois seguintes reunidos.

Urosternitos fortemente transversos, o processo intercoxal do urosternito I estreito e aguçado. Urosternito V transverso, arredondado no ápice (macho) ou alongado, o pigídio parcialmente exposto (fêmea).

Discussão. Consideramos duas espécies em Callideriphus: C. grossipes Blanchard, 1851 e $C$. tucumanus sp. nov. $C$. grossipes é espécie extremamente variável em coloração, pontuação elitral e dimensões; esta variabilidade parece estar relacionada com a distribuição geográfica e reconhecemos duas subespécies (Fig. 7): C. g. grossipes, do Brasil (Minas Gerais, Espírito Santo, São Paulo, Paraná e Santa Catarina), e $C$. grossipes flavipennis, do Brasil (Santa Catarina, Rio Grande do Sul) e da Argentina (Chaco, Entre Ríos, Buenos Aires), subespécie com diversos padrões de colorido da cabeça, das antenas, do protórax, dos élitros, da face ventral e dos fêmures.

\section{Chave para espécies de Callideriphus}

1. Pronoto com rugas grossas, marcadas e não confluentes. Lados do protórax com pontos grossos, rasos, irregularmente adensados. (Figs. 1-5). BRASIL (Minas Gerais, Espírito Santo ao Rio Grande Sul), ARGENTINA (Chaco, Entre Rios, Buenos Aires)

C. grossipes Blanchard, 1851

Pronoto muito finamente rugoso, as rugas rasas e muito aproximadas a confluentes, aspecto reticulado no disco. Lados do protórax densamente pontuado-reticulados. (Colorido geral castanho; élitros com áreas amareladas de extensão variável). (Fig. 6). ARGENTINA (Tucumán) C. tucumanus $\mathbf{S p . n o v}$.

\section{Callideriphus grossipes grossipes Blanchard, 1851}

(Figs. 1, 2, 7)

Callideriphus grossipes Blanchard in Gay, 1851: 487; Cerda, 1986: 37; Monné, 1994: 39 (cat.).

Callideriphus grossipes var. brasiliensis Melzer, 1923: 10; Monné, 1994: 39 (cat.).

Callideriphus grossipes brasiliensis Melzer, 1923: 10. Syn. nov.

Callideriphus rubricollis Melzer, 1934: 79; Monné, 1994: 40. Syn. nov.

Callideriphus grossipes foi originalmente descrita do Chile, de "las províncias del sur" (BLANChard 1851). Entretanto, como a descrição foi baseada em único exemplar (4 linhas de comprimento por 1 linha de largura umeral), não poderiam ser citadas "províncias". O holótipo, muito provavelmente, estaria depositado no MNHN como ocorre com o material descrito por Blanchard (HoRn \& KAHLE, 1935). FAIRMAIRE \& GERMAIN (1859) repetiram a descrição original o que indica que não examinaram exemplares. Philippi (1887: 158), no seu catálogo dos coleópteros do Chile, arrolou C. grossipes para "Chile australis".

Melzer (1923, 1927), antes de descrever Callideriphus grossipes var. brasiliensis, remeteu alguns exemplares para Bruch na Argentina. Bruch solicitou material para comparação aos Museus de Valparaíso e Santiago, mas não teve êxito em nenhuma dessas instituições. MELzer (1923), então, resolveu descrever essa forma como variedade de $C$. grossipes.

Cerda (1986) considerou Callideriphus grossipes como nomen dubium e declarou: "Los tipos de algunas de estas especies no fueron vistos por estar perdidos o destruidos... En vários casos se considera que hubo error en mencionarlas para Chile, cuando pertenecían a la fauna de otros países."

Em visita ao MNHN, Monné (comunicação pessoal) não pode localizar o holótipo. $\mathrm{O}$ mesmo aconteceu após exaustiva busca com o auxílio de G. Tavakilian, por um dos autores (DSN).

Concluímos que Callideriphus grossipes não pertence à fauna chilena e, provavelmente, o holótipo está perdido. A forma que mais se adapta à descrição de $C$. grossipes Blanchard, 

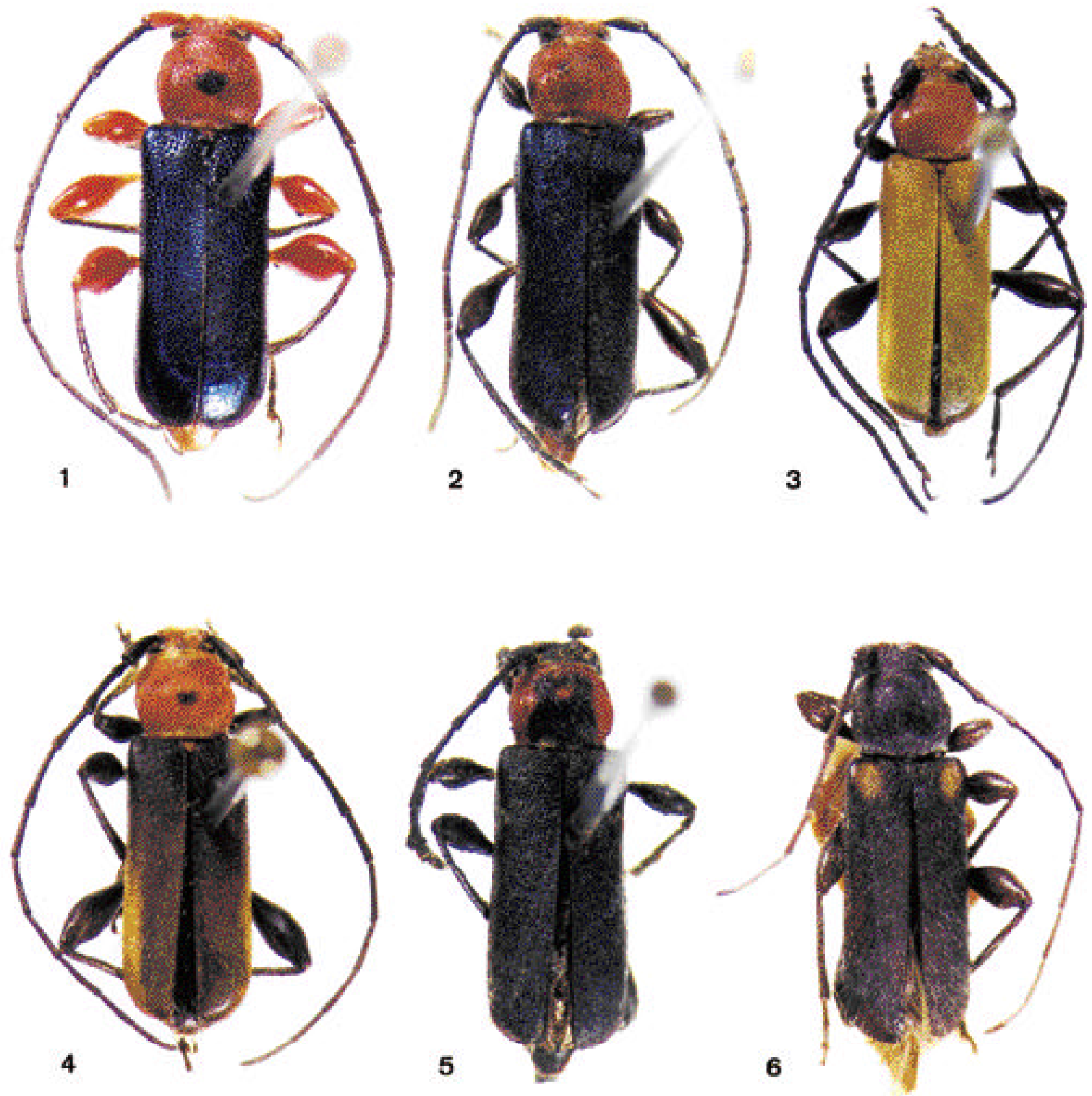

Figs. 1-6. 1, Callideriphus grossipes grossipes Blanchard, 1851, macho, Espírito Santo, Santa Tereza, comprimento 6,5 mm; 2, C. rubricollis Melzer, 1934, fêmea, Santa Catarina, São Bento do Sul, 6,6 mm; 3, C. g. flavipennis Melzer, 1934, forma típica, macho, Santa Catarina, Seara (Nova Teutônia), 7,3 mm; 4, C. g. flavipennis, forma intermediária, macho, Santa Catarina, Seara (Nova Teutônia), 7,8 mm; 5, C. signaticollis Melzer, 1934, holótipo fêmea; 6, C. tucumanus sp. nov., holótipo macho, comprimento, 5,9 mm. 
1851 é C. grossipes var. brasiliensis Melzer, 1923, portanto, julgamos apropriado considerá-la como uma subespécie sinônima.

C. grossipes (Fig. 1) apresenta: cabeça, escapo e fêmures, vermelhos; protórax vermelho com mancha preta no disco; élitros azul-metálicos brilhantes, com pontuação densa até pouco além do meio e terço apical quase liso, a pubescência moderadamente densa até o meio e mais esparsa para o ápice; face ventral do corpo vermelha. BLANCHARD (1851) referiu-se a "elytris... nigro-cyaneis" e "enteramente de un negro que frisa ligeramente el azulado.” MELzer (1923) referiu-se à descrição da coloração dos élitros feita por Blanchard, mas os exemplares que dispunha tinham élitros "dum azul bonito e bem vivo" e descreveu esta forma como a variedade brasiliensis de $C$. grossipes.

Melzer (1934), baseado em único exemplar procedente de Mafra, Santa Catarina, descreveu C. rubricollis (Fig. 2), a qual considerou "uma especie muito visinha de $C$. grossipes Blanch. var. brasilensis (sic) Melz. mas differindo pela coloração e punctuação." Verificamos que o holótipo de C. rubricollis tem cabeça e antenas pretas, pronoto sem mancha central preta, élitros mais densamente pontuados, portanto de um azulmetálico menos brilhante, urosternitos castanhos e pernas castanhas com base dos fêmures mais clara. O exame de um maior número de exemplares permitiu constatar que a cabeça pode apresentar-se vermelha com o dorso preto; o escapo pode ser avermelhado; o restante das antenas é preto (como em $C$. grossipes); o pronoto pode apresentar mancha dorsal preta; os urosternitos podem ser vermelhos; e os fêmures podem variar desde pretos até vermelhos. Assim, o único caráter para distinguir C. rubricollis de $C$. grossipes é a leve diferença na pontuação elitral que também ocorre nos indivíduos de $C$. grossipes procedentes da parte meridional da distribuição (Paraná). Dessa forma, consideramos C. rubricollis sinônima de C. grossipes.

Melzer (1923) descreveu C. grossipes variedade brasiliensis com base em 20 exemplares de Minas Gerais, Passa Quatro (Fig. 7, círculo branco). No MZSP encontram-se 19 dos exemplares citados, que são considerados síntipos de $C$. grossipes brasiliensis Melzer, 1923, a saber:

BRASIL. Minas Gerais: Passa Quatro (Fazenda dos Campos), fêmea, X.1915, E. Jaeger col.; macho, fêmea, XI.1915, J. F. Zikán col.; fêmea, 14.XI.1915, J. F. Zikán col.; macho, 2 fêmeas, 15.XI.1915, J. F. Zikán col.; 2 machos, 1 fêmea, 23.XI.1915, J. F. Zikán col.; fêmea, 25.XI.1915, J. F. Zikán col.; macho, 28.XI.1915, J. F. Zikán col.; macho, 3.XII.1915, J. F. Zikán col.; macho, 23.XII.1915, J. F. Zikán col.; 3 machos, 5.X.1916, J. F. Zikán col.; macho, 15.XI.1916, J. F. Zikán col.; fêmea, 19.I.1918, J. F. Zikán col.

Material adicional examinado (Fig. 7, círculos brancos). Espírito Santo: Santa Tereza, 4 machos, 2 fêmeas, 26.X.1964, 2 machos, 5.XI.1964, 1 macho, 1 fêmea, XI.1964, C. Elias (DZUP). São Paulo: Agudos, macho, 1909, H. Reda col. (MZSP, 16572); São Paulo, macho, XII.1934, B. B. col. (MZSP). Paraná: Castro, fêmea, 15.XI.1971, Moure \& Mielke col. (DZUP); Curitiba, 2 machos, 1 fêmea, XII.1941, [sem nome do coletor] (MZSP); Piraquara, 10 machos, 5 fêmeas, 10.XI.1968, Moure col. (DZUP); Ponta Grossa, 1 macho, 1 fêmea, 1940, P. Machado col. (MZSP); macho, X.1946, Col. Justus (DZUP).
Exemplares intermediários entre $C$. g. grossipes e " $C$. rubricollis" têm: cabeça e protórax vermelhos; pronoto com ou sem mancha dorsal preta; escapo preto; fêmures castanhos ou castanho-avermelhados, ou castanhos com os pedúnculos amarelados; face ventral preta ou com esternos torácicos castanhos e urosternitos escuros ou acastanhados; élitros azul-escuro-metálicos pouco brilhantes; pontuação elitral fina e densa; pilosidade dos élitros densa em toda superfície.

Material examinado (Fig. 7, círculos divididos). Paraná: Morretes (975 m), 5 machos, 8 fêmeas, 13.XII.1969, Moure \& Giacomel col. (DZUP); Piraquara, macho, 6 fêmeas, 10.XI.1968, Moure col., 5 machos, 2 fêmeas, XI.1968, Moure, Mielke \& Dairiki col. (DZUP); Ponta Grossa, macho, 1942, Justus col. (DZUP). Santa Catarina: Mafra, macho, XII.1930, A. Maller col. (Holótipo de C. rubricollis, MZSP); Rio Negrinho, macho, I.1971, A. Maller col. (DZUP); São Bento do Sul (Rio Vermelho), 1 macho, 1 fêmea, III.1962, Dirings (MZSP); macho, XII.1966, A. Maller col. (DZUP).

Callideriphus grossipes flavipennis Melzer, 1934, stat. nov. (Figs. 3-5, 7)

Callideriphus flavipennis Melzer, 1934: 78; Monné, 1994: 39 (cat.). Callideriphus signaticollis Melzer, 1934: 80; Monné, 1994: 40 (cat.). Syn. nov.

Callideriphus signaticollis m. frontalis Fuchs, 1961: 8; Monné, 1994: 40 (cat., syn.).

Espécie que varia no colorido da cabeça, do escapo, do protórax, do escutelo, dos élitros, da face ventral e dos fêmures.

A forma típica de C. grossipes flavipennis (Fig. 3) tem cabeça, protórax, escutelo e fêmures, vermelhos; élitros amarelados ou com ponta preta; antenas, meso- e metasterno, tíbias e urosternitos, acastanhados; pontuação elitral fina, densa até os ápices; pilosidade densa até os ápices.

Material examinado (Fig. 7, triângulos sombreados). Santa Catarina: Seara (Nova Teutônia), macho, 28.X.1933, Plaumann col. (MZSP, cótipo); macho, IX.1933, macho, X.1933,B. Pohl col. (DZUP), 4 machos, 4 fêmeas, IX.1957, 2 machos, 3 fêmeas, X.1962, 1 macho, 2 fêmeas, IX.1965, 33 machos, 32 fêmeas IX.1966, F. Plaumann col. (DZUP), 1 macho, 1 fêmea, IX.1965, 4 machos, 1 fêmea, IX.1966, F. Plaumann col (MZSP). Rio Grande do Sul: Marcelino Ramos, fêmea, 25.X.1939, [sem nome do coletor]; fêmea, VIII.1940 [sem nome do coletor] (MCNZ); Santa Maria, fêmea, 9.X.1988, M. Hoffmann col. (MCNZ).

Exemplares intermediários entre $C$. grossipes flavipennis e "C. signaticollis Melzer" apresentam (Fig. 4): cabeça preta ou vermelha; pronoto vermelho com ou sem mancha preta (de dimensões variáveis); escutelo de amarelado a castanho; face ventral (prosterno exceto) e pernas, pretas; élitros castanhos ou pretos com uma faixa amarelada, longitudinal e ao longo da epipleura; pontuação elitral fina e densa até os ápices.

Material examinado (Fig. 7, triângulo branco). Santa Catarina: Seara (Nova Teutônia), 2 machos, X.1940, F. Plaumann col. (MZSP); fêmea, X.1941, F. Plaumann col. (MNRJ); 2 machos, 1 fêmea, IX.1965, 3 machos, 3 fêmeas, IX.1966, F. Plaumann col. (MZSP); 5 machos, 8 fêmeas, IX- X.1966, F. Plaumann col. (DZUP). 


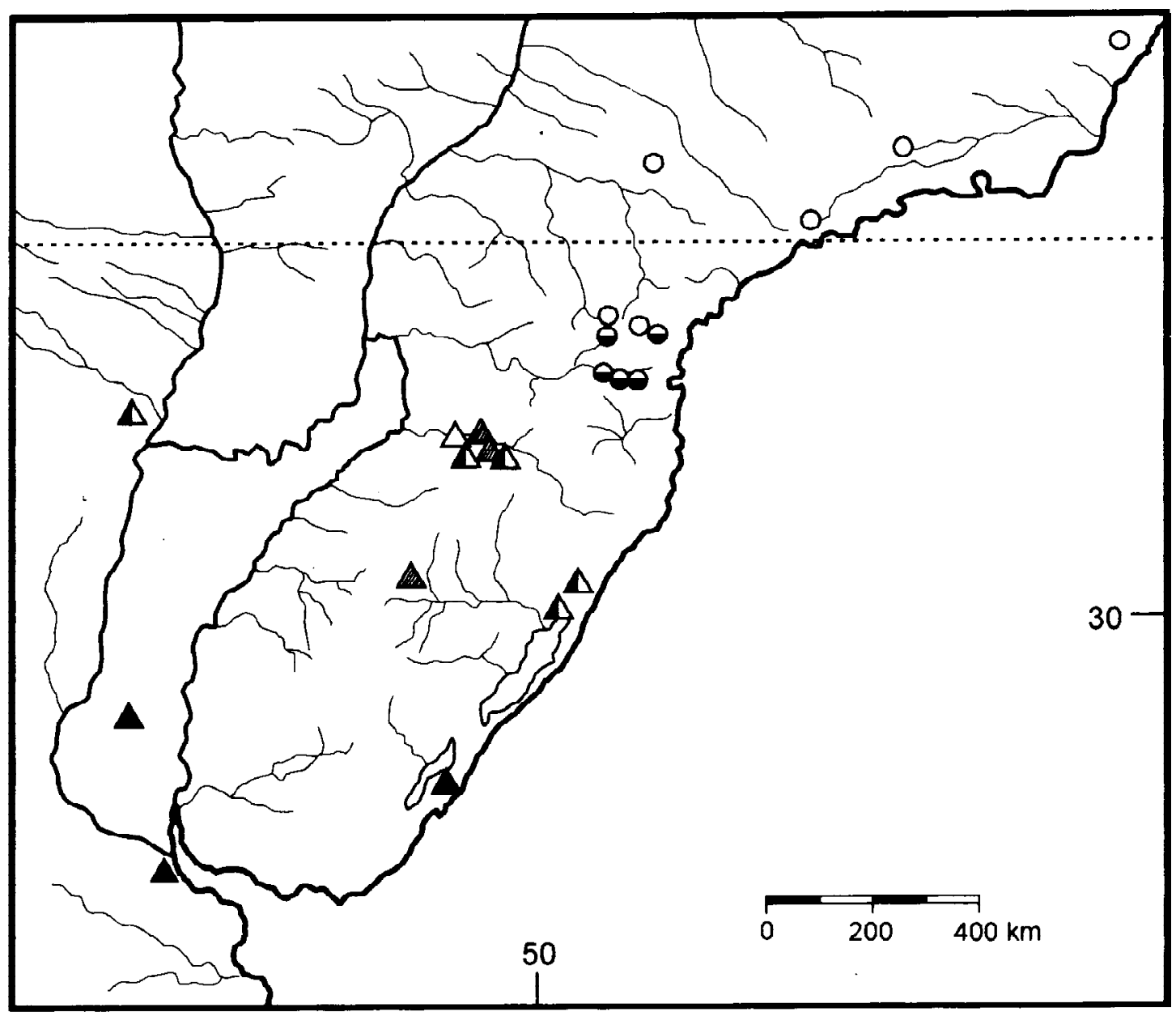

Fig. 7. Distribuição geográfica de Callideriphus grossipes: círculos brancos, Callideriphus grossipes grossipes, forma típica; círculos divididos, C. rubricollis e formas intermediárias entre C. rubricollis e C. g. grossipes; triângulos sombreados, C. g. flavipennis, forma típica; triângulo branco, formas intermediárias entre C. g. flavipennis e C. signaticollis; triângulos divididos, C. signaticollis, forma típica; triângulos pretos, formas meridionais de C. g. flavipennis.

Exemplares que correspondem a “C. signaticollis" (Fig. 5): cabeça, antenas, escutelo, élitros, e face ventral (exceto prosterno), pretos; protórax vermelho com mancha central, larga, que vai da base até quase o ápice, preta; essa mancha pode envolver pequena mancha vermelha arredondada; pontuação elitral até corrugada; pilosidade elitral densa. Fêmures pretos ou com a base amarelada.

Material examinado (Fig. 7, triângulos divididos). Santa Catarina: Seara (Nova Teutônia), fêmea, F. Plaumann col. (MZSP). Rio Grande do Sul: Marcelino Ramos, macho, 25.X.1939 [sem nome do coletor], fêmea, 5.X.1940 [sem nome do coletor] (MZSP); Porto Alegre, fêmea, 25.XI.1931 [sem nome do coletor no rótulo de procedência, mas P. Buck col., segundo Melzer, 1934: 80] (MZSP, holótipo); São Francisco de Paula (Fazenda 3 Cachoeiras), macho, 24.XI.1998, Franceschini col. (MCNZ).

Exemplares do Chaco (Argentina) concordam com a forma acima, mas têm só a parte superior da cabeça preta e o pedúnculo dos fêmures amarelado.
Material examinado: ARGENTINA. Chaco: macho, ex-col. Bosq (MNRJ); La Escondida, macho, 28.XI.1936, Denier col. (MNRJ).

Forma intermediária entre " $C$. signaticollis" e exemplares mais meridionais: cabeça, antenas, protórax, escutelo, élitros, face ventral e pernas, pretos; ou com os lados do protórax castanho-amarelados, estreita faixa epipleural amarelada, face ventral castanha, fêmures castanhos com pedúnculo um pouco mais claro; ou cabeça vermelha, com a região dorsal preta, protórax vermelho com grande mancha negra no pronoto; élitros com áreas amareladas de extensão variável, pedúnculos dos fêmures vermelhos. Em todos os exemplares a pontuação elitral é fina e densa e a pilosidade densa em toda superfície.

Material examinado (Fig. 7, triângulos pretos). BRASIL. Rio Grande do Sul: Rio Grande (Taim), 2 machos, 2.XII.1986, M. Rosenau col. (MCNZ). ARGENTINA. Entre Ríos: macho, I.1976, Liebig col. (MZSP). Buenos Aires: Delta, fêmea, 9.XII.1944, Bridarolli col. (MNRJ). 


\section{Callideriphus tucumanus sp. nov.}

(Fig. 6)

Macho. Colorido geral castanho a castanho avermelhado; élitros mais escuros, com áreas amareladas de extensão variável no dorso e margem da epipleura amarelada.

Fronte fina e densamente pontuada, brilhante; pubescência esbranquiçada esparsa. Genas quase tão longas quanto a metade do comprimento do lobo ocular inferior. Vértice fina e densamente pontuado-rugoso. Antenas ultrapassam o ápice elitral por dois antenômeros. Escapo com pontuação fina e rasa; pubescência esbranquiçada esparsa. Antenômeros II-XI fina e densamente pontuados, a pubescência gradualmente mais adensada para os distais. Todo o pronoto com rugas longitudinais muito finas, aproximadas a confluentes e pouco marcadas e pubescência esbranquiçada, deitada, mais densa para as regiões laterais. Lados do protórax pontuadoalveolados. Élitros fina e densamente pontuado-corrugados em toda a superfície, a escultura mais fina e densa no terço posterior; pubescência esbranquiçada bem aparente, mais evidente no terço posterior. Fêmures com clavas robustas, os posteriores não atingem o ápice elitral; pontuação fina e superficial e pubescência esbranquiçada moderadamente densa.

Dimensões, mm, macho: comprimento total, 5,3 - 5,9; comprimento do protórax, 1,2-1,3; largura do protórax, 1,41,5; comprimento do élitro, 3,8-4,2; largura umeral, 1,6-1,8.

Material-tipo. Holótipo macho de ARGENTINA, Tucumán, XII.1953, ex-col. Bosq (MNRJ). Parátipo macho, idem (DZUP).

Comentários. No holótipo as áreas amareladas dos élitros estão restritas a duas pequenas manchas arredondadas na base, no lado interno dos úmeros; no parátipo, o dorso dos élitros apresenta duas largas faixas amareladas da base até o meio, além de duas áreas arredondadas no terço apical. Dessa forma, é provável que $C$. tucumanus apresente a mesma variabilidade de colorido que se observa em C. g. flavipennis.

Pelo colorido do corpo, pontuação elitral e presença de áreas amareladas nos élitros, $C$. tucumanus é semelhante às formas meridionais de $C$. g. flavipennis. Distingue-se principalmente pela escultura do pronoto com rugas muito finas, pouco marcadas e subcontíguas e pela pontuação alveolada dos lados do protórax. Nas duas subespécies de $C$. grossipes, as rugas do protórax são mais grossas, marcadas e afastadas entre sí, principalmente no terço anterior, onde são divergentes; os lados do protórax apresentam pontos grossos e rasos. Além disso, em $C$. grossipes o pronoto é subglabro, enquanto em $C$. tucumanus a pubescência é bem aparente.

Agradecimentos. A M. A. Monné (MNRJ) e G. Tavakilian (MNHN) pela exaustiva busca do material-tipo de Blanchard e a A. M. Sakakiba (DZUP) pelas fotos.

\section{REFERÊNCIAS}

Blanchard, C. E. 1851. Fauna Chilena. Insectos Coleópteros. In C. Gay: Historia física y política de Chile. Zoologia. 5: 285-563.

Cerda, M. 1986. Lista sistemática de los Cerambycidos chilenos (Coleóptera: Cerambycidae). Revista Chilena de Entomologia 14: 29-39.

Fairmaire, L. \& P. Germain. 1859. Révision des coléoptères du Chili (suite). Annales de la Societé Entomologique de France (3) 7: 483-532.

Fuchs, E. 1961. Neue cerambyciden aus südbrasilien. Pesquisas, Zoologia, 12: $5-10$.

Horn, W. \& I. Kahle, 1935. Über entomologische Sammlungen, Entomologen \& Entomo-Museologie. Entomologische Beihefte Berlin-Dahlen 2: VI+160 p.

Melzer, J. 1923. Longicórneos (Col.) do Brasil novos ou pouco conhecidos. Notas preliminares do Museu Paulista 2(4): 1-10.

Melzer, J. 1927. Longicórneos (Col.) do Brasil novos ou pouco conhecidos. Revista do Museu Paulista. 15(1): 135-202.

MelzeR, J. 1934. Novos subsídios para o conhecimento dos cerambycideos neotrópicos. Revista de Entomologia 4(1): 70-110.

Monné, M. A. 1994. Catalogue of the Cerambycidae (Coleoptera) of the Western Hemisphere. Part X. São Paulo, Sociedade Brasileira de Entomologia, $81 \mathrm{p}$.

NAPp, D. S. \& U. R. Martins. 2002a. Unabiara, um novo gênero de Heteropsini (Coleoptera, Cerambycidae). Revista Brasileira de Entomologia 46(1): 71-76.

Napp, D. S. \& U. R. Martins. 2002b. Eryphus Perty, 1832 e Tacyba, novo gênero de Heteropsini (Coleoptera, Cerambycidae). Revista Brasileira de Entomologia 46(1): 83-92.

Philippi, F. H. E. 1887. Catálogo de los Coleópteros de Chile. Anales de la Universidad de Chile 71: 619-806.

Thomson, J. 1864. Systema cerambycidarum ou exposé de tous les genres compris dans la famille des cérambycides et familles limitrophes. Mémoires de la Societe Royal des Sciences de Liège 19:1540 . 